\title{
Electronic system for control of temperature of exhaust gases and pressure in turbochargers of diesel automobile engines
}

\author{
Seher Kadirova ${ }^{1}$, Stiliyan Okishelov ${ }^{1}$, and Zhivko Kolev,"* \\ ${ }^{1}$ Department of Electronics, University of Ruse, Ruse 7017, Bulgaria \\ ${ }^{2}$ Department of Heat, Hydraulics and Environmental Engineering, University of Ruse, Ruse 7017, \\ Bulgaria
}

\begin{abstract}
The paper presents design and experimental investigation of an electronic system for control of the temperature of exhaust gases and the turbocharging air pressure in turbochargers of diesel automobile engines. The existing problems are faults in the fuel system of an engine. The indicators are changes in the values of the temperature and pressure in exact areas of the turbocharger. The presented device is a controller that monitors precisely the temperature and pressure, which are so vital for the long operation of the automobile. The control system is based on Arduino microcontroller. OLED Display has been added to visualize the obtained results. A schematic diagram of an electronic module for control of the temperature of exhaust gases and turbocharging air pressure in turbochargers of diesel automobile engines has been synthesized. The system has been investigated in laboratory conditions and practically implemented in a real automobile. As a result of laboratory experimental investigation, results were obtained for the time-monitored parameters temperature of the exhaust gases and turbocharging air pressure in the turbocharger system of a diesel automobile engine.
\end{abstract}

\section{Introduction}

There are various studies on the turbocharged diesel internal combustion engines. In [1] a procedure for selection and matching of turbochargers for diesel engines has been developed. Paper [2] presents investigation on the energy distribution in turbocharger system of a diesel engine. Different techniques used in turbocharging processes of diesel engines, in order to improve the engine efficiency and exhaust emissions, have been considered in paper [3]. In study [4] an evaluation method for the transient response performance of turbocharged diesel internal combustion engines has been proposed and analysed. Investigation [5] presents a method for evaluation of the adaptability to different altitudes of turbocharging diesel engine systems. In [6] an experimental study on the performance and economy parameters of a diesel internal combustion engine with variable nozzle turbocharger is accomplished. Paper [7] presents an investigation of the exhaust

* Corresponding author: zkolev@,uni-ruse.bg 
gases' pressure on the turbocharger performance. Mathematical model for evaluation the coupling of an inverted Brayton cycle - based recovery unit with a turbocharged diesel engine, has been considered in [8]. In [9] a performance analysis of a turbocharged twostroke diesel engine, operating at various ambient conditions has been presented. The research [10] is focuses on determination of some heat transfer parameters of processes in the intake system of a piston engine with a turbocharger system. Numerical investigation of combustion processes in a turbocharged diesel engine has been considered in [11].

Paper [12] presents a nonlinear controller for the air-path system of a turbocharged diesel engine. One of the controlled parameters is the air pressure in the turbocharger outlet. Measure of pressures and temperatures in selected sections of intake and exhaust circuits of turbocharged diesel engine has been considered in [13]. The pressures have been measured by strain gauge transducers. For measure of the temperatures platinum resistance thermometers and K-type thermocouples have been used. In [14] the heat transfer process in the air duct between turbocharger and intercooler has been studied. One of the measured parameters used for determination of the heat flux, is the pressure of the hot air after the turbocharger. Study [15] presents a procedure of exhaust gas temperature measurements by thermocouples in turbocharged marine internal combustion engines. A linear parameter varying polytopic observer of the exhaust gases' pressure in turbocharged automotive diesel engine has been considered in [16]. In [17] the influence of the air pressure and air temperature after the turbocharger on the pressure in the cylinders of turbocharged a fourstroke diesel engine has been discussed. Investigation of the influence of some operation parameters of a diesel engine on the exhaust gas temperature has been considered in [18]. In [19] an experimental study for calculation the heat quantity by electronic system has been presented. The system reliability also has to be considered. In [20] a case study and some prescriptions have been suggested to increase the operational reliability. The relation between the system of transformation of matter, energy and information, the technical system and the executing bodies of the technical system also has to be considered [21] for having a steady model development.

The paper presents design and experimental investigation of an electronic system for monitoring of the temperature of exhaust gases and the turbocharging air pressure in turbochargers of diesel automobile engines. The presented device is a controller that monitors precisely the temperature and pressure, which are so vital for the long operation of the automobile.

These two factors determine the service life of the turbocharger in every internal combustion engine. With the spread of more stringent measures related to internal combustion engines, the temperature requirements to the components of each internal combustion engine become very high. In this way, when a vehicle is equipped with such a monitoring system, unwanted damage will be avoided and timely alert will be given before it occurs. The monitoring system is an easy to operate and reliable system because it is not equipped with complex components and there is a visual connection with the driver.

\section{Methodology}

Some of the most important parameters that need to be monitored in the operation of modern diesel engines are the temperature of the exhaust gases in the inlet and the air pressure in the outlet of the turbocharger. The cylinder pressure in the internal combustion engines depends on the fuel-burning rate during the premixed burning phase. The increasing of the cylinder pressure leads to good combustion and increasing of the rate of heat release.

The exhaust gas temperature in the internal combustion engine, measured in characteristic control cross-sections of its thermal and flow system, can be a valuable 
source of diagnostic information about technical condition of elements limiting particular engine workspaces, including the supercharging system, the fuel supply system, and the working medium exchange system. In standard measuring systems installed on vehicle engines equipped with pulse turbocharging system, the exhaust gas temperature is measured at the outlets of particular cylinders, and at the turbocharger turbine inlet and outlet [15].

The proposed electronic device is implemented on the basis of ATMEGA 2560. It contains all the necessary elements for normal operation, expect of the power supply module and the interface for communication between the microcontroller and the device, through which the program code is set. The easiest implementation of a project containing microcontroller control and data visualization is platform such as Arduino. The platform was used in this project due to the wide range of peripherals and their low price. The problem with this platform is the limited memory of the controller and therefore the optimal option is Arduino MEGA 2560. Blue Oled display SH1106 128X64 - pixels is added as a periphery which is operating on the basis of $\mathrm{I} 2 \mathrm{C}$ communication and allowing the use of only 2 pins. The picture is shown in Fig. 1.

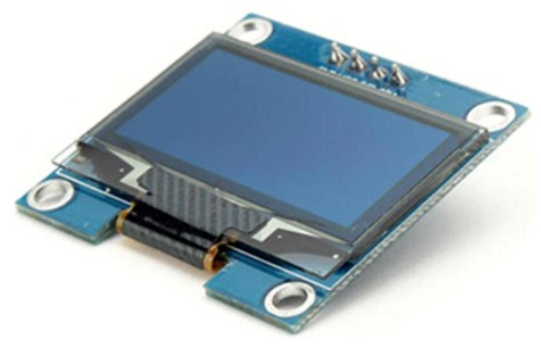

Fig. 1. OLED Display - SH1106.

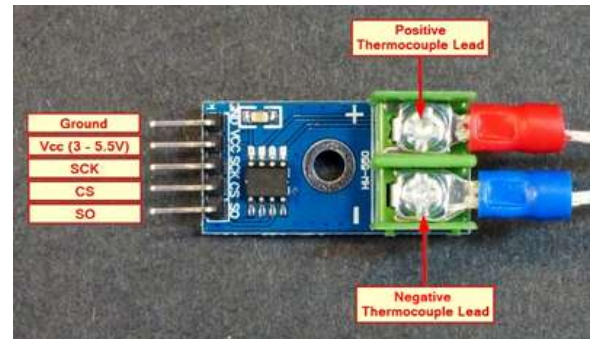

Fig. 2. Thermocouples MAX6675K.

The MAX6675K Thermocouples amplifier each having digital serial data output and supplied along with K-type thermocouple is connected ATM2560. It is selected and complies with the standard used in most of vehicles using BOSCH systems. The graphic is presented in Fig. 2.

The pressure sensor MPX4250AP (Fig. 3), operates with analog signal, in the range -2.5 $\sim 2.5$ bar. In this case this is a voltage from 0 to $5 \mathrm{~V}$, which is then converted to pressure, by the algorithm in the program.
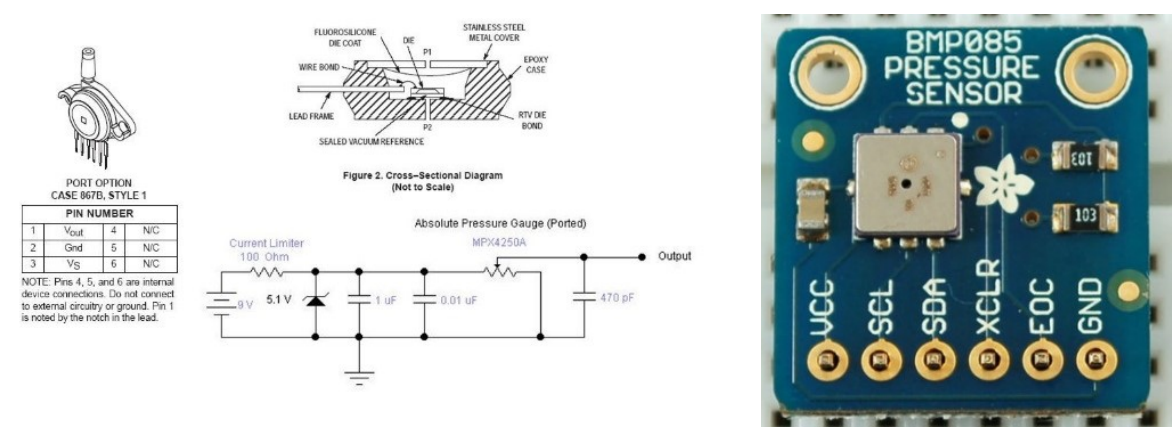

Fig. 3. MPX4250AP Sensor.

Fig. 4. Atmosphere pressure sensor BMP085.

The role of the Adafruit BMP085 Barometric Sensor is to make the necessary correction in the MPX4250AP readings, as the atmospheric pressure changes depending on the altitude, and the weather conditions. 


\section{Results and discussion}

Fig. 5 presents the diagram of a conventional system with the additionally placed sensors. In position 11 is placed the air pressure sensor, and in 13 is the EGT sensor, respectively.
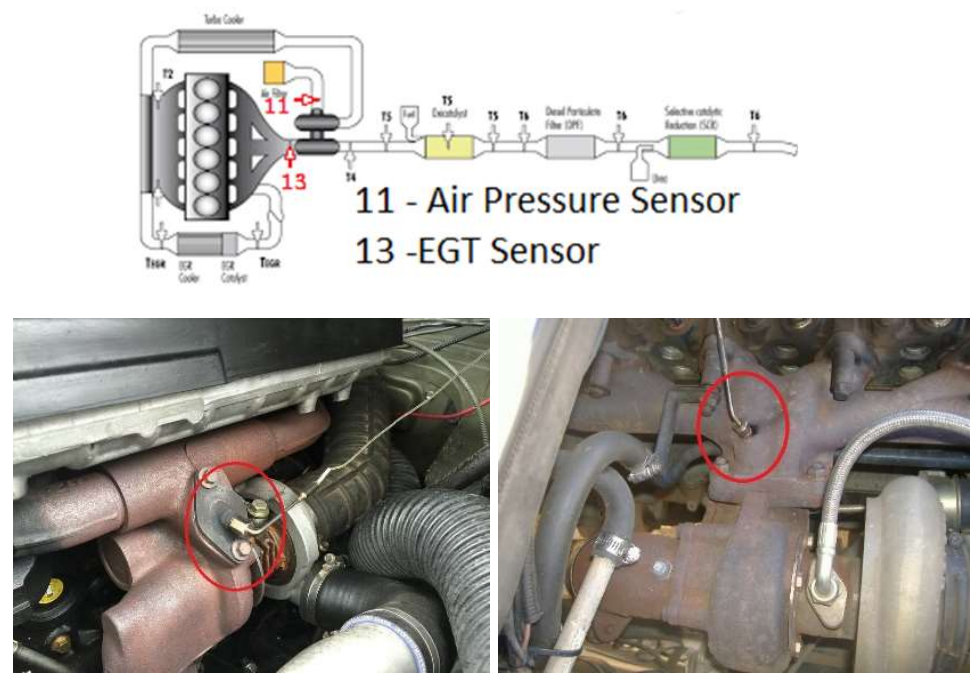

Fig. 5. Diagram of the system with the additionally placed sensors and experimental pictures.

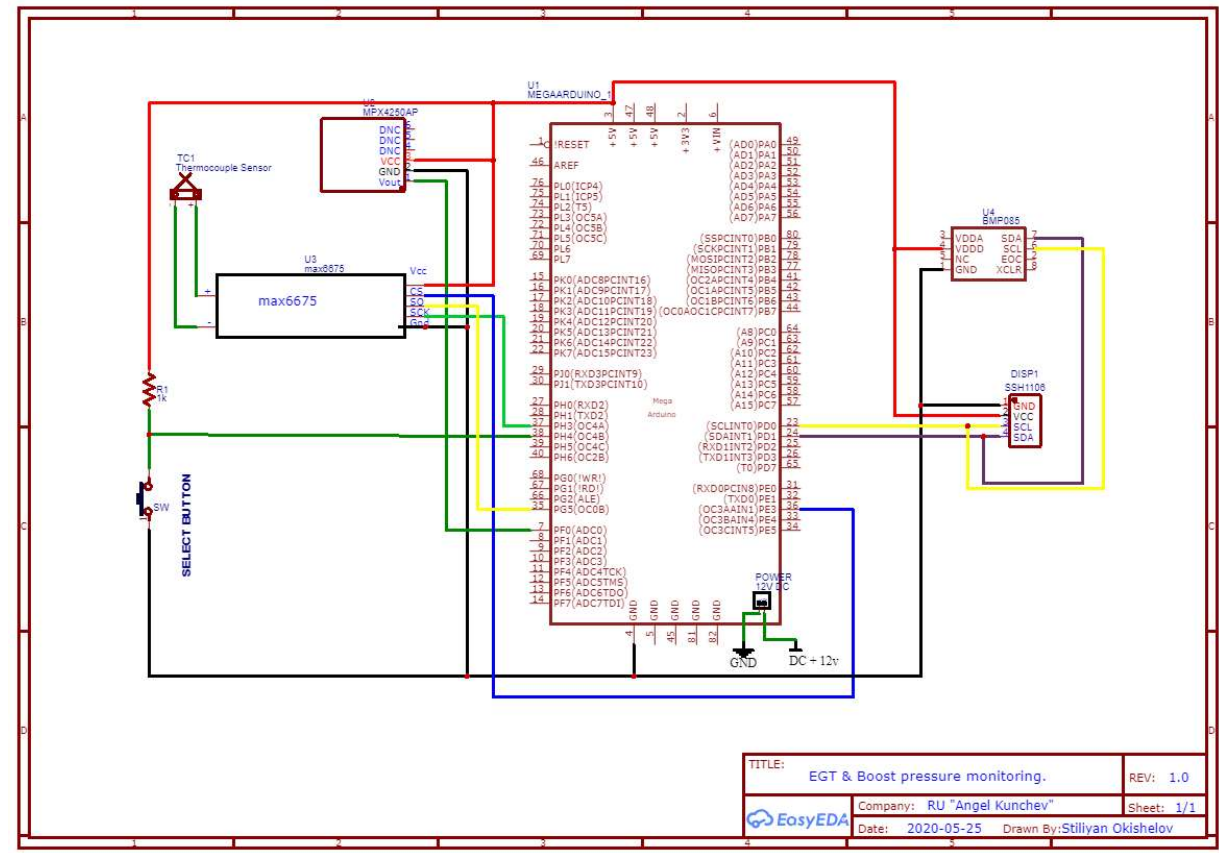

Fig. 6. Electrical schematic diagram of the system.

Fig. 6 presents the electrical schematic diagram of the system. The system has been investigated in laboratory conditions and practically implemented in a real automobile.

The button can be optionally selected, depend on the place where it will be installed to ensure easy access. Its role is to change the measurement mode. When the button is pressed 
once, it changes the mode of the measuring program. The modes in this case are two "EGT Temperature measurement", and "TCP Turbocharger pressure leaching". This mode switch is circular, by pressing the button again the modes switch between both.

The temperature measured by the sensor, which is in analogic form, is given to the inputs of the digital converter MAX6675. The signal is converted into a digital 12bit SPI signal and transmitted to the microcontroller, which in our case is mounted on the Arduino MEGA2560 platform. The signal is processed by the controller, based on the program compiled in it. After processing the information, the controller sends a signal via the $\mathrm{I}^{2} \mathrm{C}$ bus to the display, which displays the read temperature from the thermo-complement pair.

The program has a function to store the minimum and maximum values read by the sensor.

Fig. 7 presents pictures of the experimental test board and results for the temperature and the pressure, achieved during the experiments.
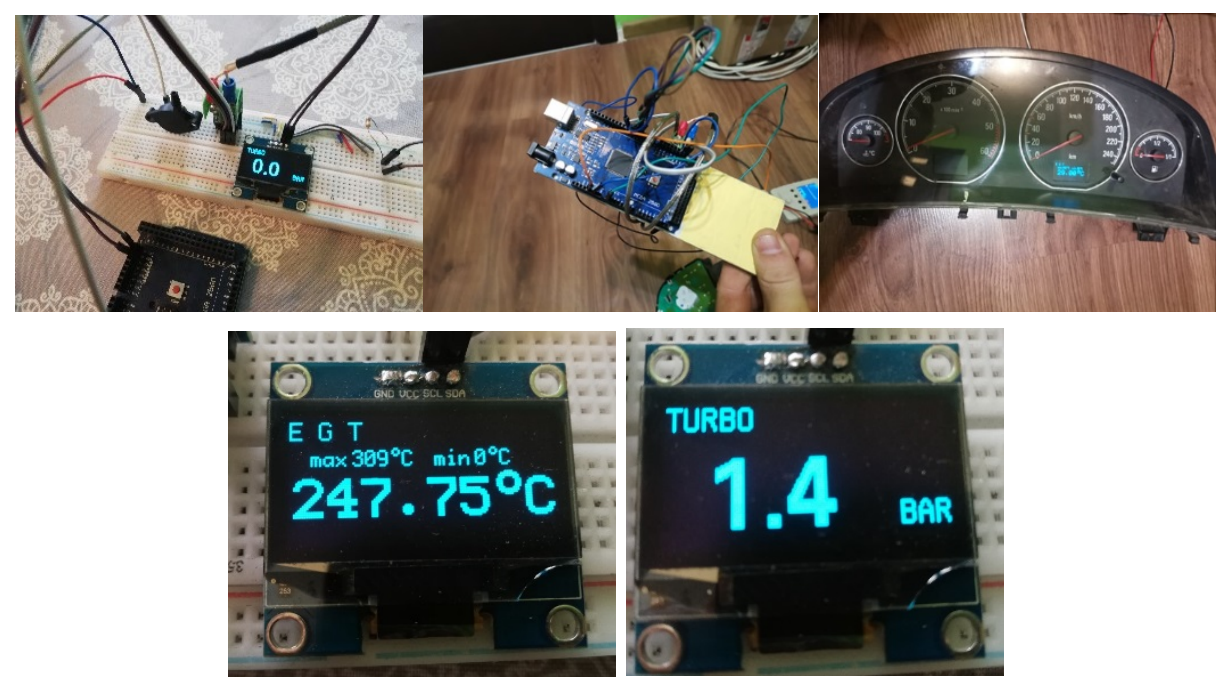

Fig. 7. Test board pictures and results.

The button can be used to switch to another monitored parameter. In our case, this is the pressure of the turbocharger. This pressure is read on the basis of a measured voltage at one of the microcontroller's analogic inputs, converted to a constant " $0-255$ " and then sent to a subprogram in the main program to be calculated for converting the value in bars. In addition to the circuit, the module BMP085 is used, which appears as a correction of the value obtained from the pressure sensor. Then the current value is displayed.

By using an oscilloscope, we examine analogue signals sent to the microprocessor from the real pressure sensor. It is given a voltage signal in the range $0 \sim 5 \mathrm{~V}$. The range of the sensor is $(-0.5 \sim 1.5$ bar $)$. This means that it is also possible to measure vacuum. In Fig. 8 a) a voltage of $0.6 \mathrm{mV}$ is measures, which after processing by the algorithm in the program, is equal to -0.5 bar. In Fig. 8 b) the measured voltage is $1.88 \mathrm{~V}$ which corresponds to an absolute 0 bar. This is because as mentioned above the sensor range is $-0.5 \sim 1.5$ bar and the operating voltage is $0 \sim 5 \mathrm{~V}$. This makes it possible to measure a vacuum. In Fig. $8 \mathrm{c}$ ) the measured voltage is $2.88 \mathrm{~V}$ which according to the algorithm corresponds to $0.5 \mathrm{bar}$. In Fig. $8 \mathrm{~d}$ ) the measured voltage is $3.88 \mathrm{~V}$, corresponding to 1.0 bar. In Fig. 8 e) a voltage of $4.88 \mathrm{~V}$ corresponding to the maximum pressure that the sensor can measure $(1.5 \mathrm{bar}$ is monitored). Although the sensor operates in the range of $0 \sim 5 \mathrm{~V}$, the entire range is never used to avoid unwanted and unrealistic values, even damage from overloading the components. 
Fig. 8 presents analogic signals $0 \sim 5 \mathrm{~V}$ for Pressure sensor, taken by an oscilloscope.

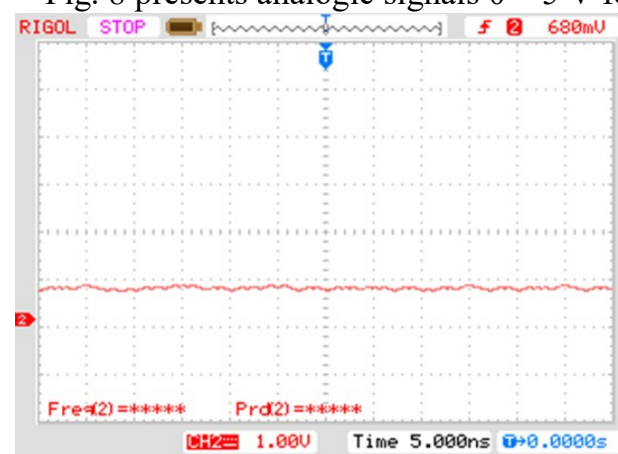

a) Vacuum 0.5 bar

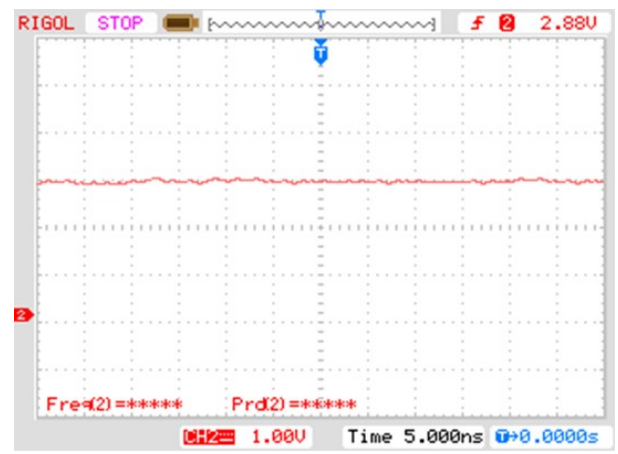

c) Pressure 0.5 bar

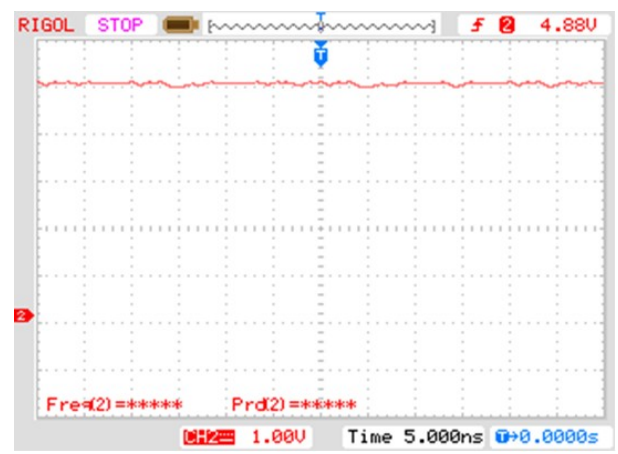

e) Pressure 1.5 bar

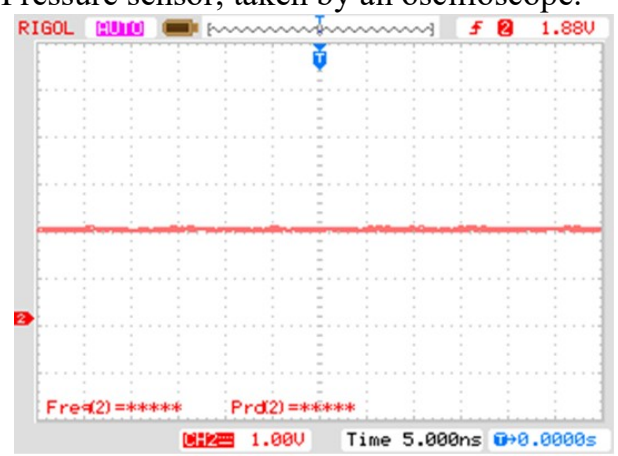

b) Pressure 0.0 bar

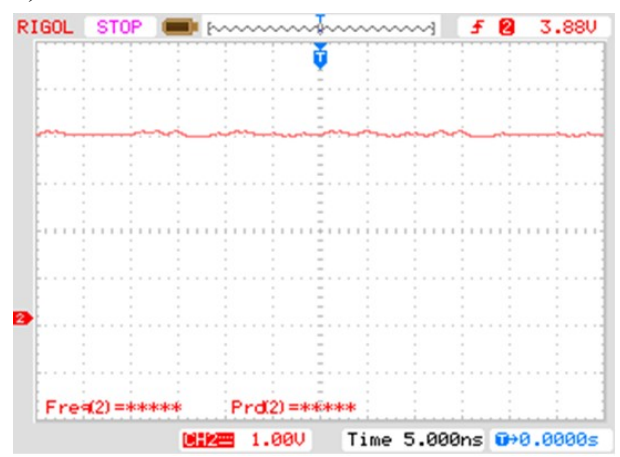

d) Pressure 1.0 bar

Fig. 8. Pressure sensor signals.

Fig. 9 presents results of SPI communication. The waveforms are taken using an oscilloscope. A series of diagrams below visualizing the digital SPI communication, through which the temperature sensor MAX6675 communicates with the microcontroller using the built-in analog-to-digital converter, has been presented. Fig. 9 a) presents the waveforms of a standard SPI communication, as Fig. 9 b), c) and d) the SPI communication signals at $1 \mathrm{~V}, 5 \mathrm{~V}$ and $10 \mathrm{~V}$ respectively. 


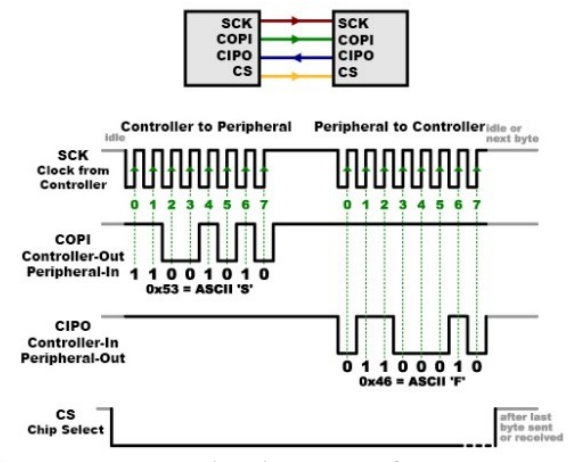

a) SPI Communication waveforms

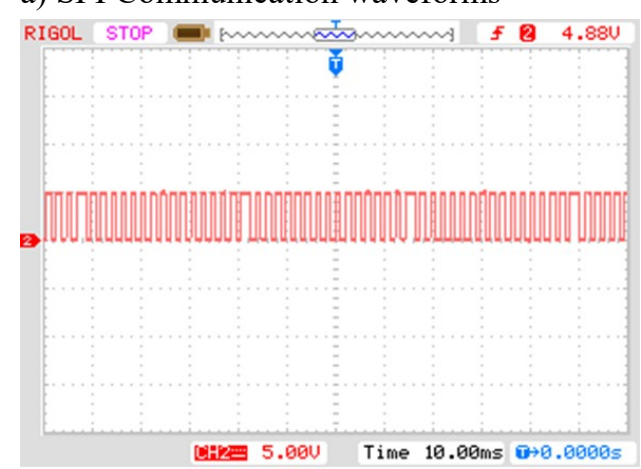

c) $5 \mathrm{~V}$

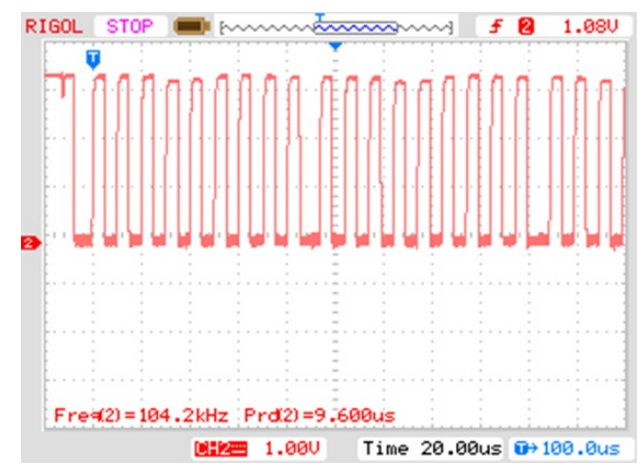

b) $1 \mathrm{~V}$

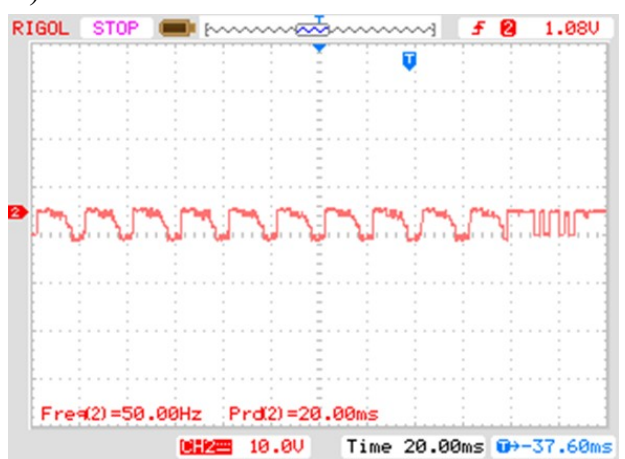

d) $10 \mathrm{~V}$

Fig. 9. SPI signals waveforms.

\section{Conclusion}

A schematic diagram of an electronic module for temperature of exhaust gases and turbocharging air pressure in turbochargers of diesel automobile engines has been synthesized.

As a result of laboratory experimental investigation, results were obtained for the timemonitored parameters temperature of the exhaust gases and turbocharging air pressure in the turbocharger system of a diesel automobile engine.

Last but not least the developed electronic module, installed in a real automobile continuously monitors the temperature and pressure in the specific zone of the turbocharger. The driver can be informed in time about the malfunction and prevent a fatal result in the turbocharger.

As a future work the project can be have additional options for monitoring the pressure and temperature of the lubricant. It is required due to the imposed environmental requirements that reduce the performance of the components used in modern internal combustion engines. One of the main causes of engine failure is temperature dependence and lack of lubricant or problem with its delivery (the pressure). 


\section{References}

1. K. Emara, A. Emara, El Sayed Abdel Razek, Turbocharger selection and matching criteria in a heavy duty diesel engine, International Journal of Scientific and Engineering Research 7, 12 (2016)

2. Jianbing Gaoa, Haibo Chenc, Guohong Tianb, Chaochen Maa, Fei Zhua, An analysis of energy flow in a turbocharged diesel engine of a heavy truck and potentials of improving fuel economy and reducing exhaust emissions, Energy Conversion and Management 184, (2019)

3. M. Muqeem, M. Ahmad, A. F. Sherwani, Turbocharging of diesel engine for improving performance and exhaust emissions: A review, Journal of Mechanical and Civil Engineering 12, 4 (2015)

4. Shuo Liu, Yi Cui, Yi Wang, Kangyao Deng, Sheng Liu, An evaluation method for transient response performance of turbocharged diesel engines, Energy 182 (2019)

5. Mingyang Yang, Yuncheng Gu, Kangyao Deng, Zhenhuan Yang, Yangjun Zhang, Analysis on altitude adaptability of turbocharging systems for a heavy-duty diesel engine, Applied Thermal Engineering 128 (2018)

6. Jiaqiang Ea, Xiaohuan Zhaoa, Liangsheng Qiua, Kexiang Weic, Zhiqing Zhanga, Yuanwang Denga, Dandan Hana, Guanlin Liua, Experimental investigation on performance and economy characteristics of a diesel engine with variable nozzle turbocharger and its application in urban bus, Energy Conversion and Management 193 (2019)

7. A. Reihania, J. Hoarda, S. Klinkertc, Chih-Kuang Kuanc, D. Stylesc, G. McConvillec, Experimental response surface study of the effects of low-pressure exhaust gas recirculation mixing on turbocharger compressor performance, Applied Energy 261 (2020)

8. D. Di Battista, R. Carapellucci, R. Cipollone, Integrated evaluation of Inverted Brayton cycle recovery unit bottomed to a turbocharged diesel engine, Applied Thermal Engineering 175 (2020)

9. Ü. Güneş, Y. Üst, A. Sinan Karakurt, Performance analysis of turbocharged 2-stroke diesel engine, Proceedings of International Conference on Engineering and Natural Science (2016)

10. L. V. Plotnikov, B. P. Zhilkin, Specific aspects of the thermal and mechanic characteristics of pulsating gas flows in the intake system of a piston engine with a turbocharger system, Applied Thermal Engineering 160 (2019)

11. Z. Petranović, M. Sjerić, I. Taritaš, M. Vujanović, D. Kozarac, Study of advanced engine operating strategies on a turbocharged diesel engine by using coupled numerical approaches, Energy Conversion and Management 171 (2018)

12. M. Hirata, T. Hayashi, M. Takahashi, Y. Yamasaki, S. Kaneko, A nonlinear feedforward controller design taking account of dynamics of turbocharger and manifolds for diesel engine air-path system, IFAC papers online, 52-5 (2019)

13. G. Zamboni, A study on combustion parameters in an automotive turbocharged diesel engine, Energies (2018)

14. S. Kaul, T. Joshi, L. Varshney, Analysis of hot air duct between turbocharger and intercooler, Materials Today: Proceedings (2020)

15. Z. Korczewski, Exhaust gas temperature measurements in diagnostics of turbocharged marine internal combustion engines Part I Standard measurements, Polish Maritime Research 1(85), 22 (2015) 
16. D. Dubic, O. Sename, D. Bresh-Pietri, A. Halle, C. Gauthier, Exhaust pressure LVP observer for turbocharged diesel engine on-board diagnosis, IFAC papers online, 51-24 (2018)

17. M. S. Oun, S. A. Farhat, M. A. 1rabeei, The effect of turbocharger pressure and intercooler temperature on engine performance, Journal of Engineering Research (University of Tripoli, Libya) 23 (2017)

18. B. Wu, Zhi Jia, Zhen guo Li, Guang yi Liu, Xiang lin Zhong, Different exhaust temperature management technologies for heavy-duty diesel engines with regard to thermal efficiency, Applied Thermal Engineering 186 (2021)

19. K. Yordanov, I. Hadzhidimov, P. Zlateva, Electronic equipment measuring device for heat quantity through a flat wall, E3S Web Conf. 207 (2020)

20. J. Garipova, A. Georgiev, T. Papanchev, D. Zlatev, Operational Reliability Assessment of Systems Containing Electronic Elements, Proceedings of $2^{\text {nd }}$ International Scientific Conference "Intelligent Information Technologies for Industry" (2017).

21. A. Manukova-Marinova, Design of technical systems by functional-structural analysis, 2020 7th International Conference on Energy Efficiency and Agricultural Engineering, EE and AE 2020 - Proceedings, (2020) 